\title{
An Exploratory Research on PCC Application of Crystalline Limestone: Effects of Limestone Crystallographic Characteristicson Hydraulic Activity
}

\author{
Ye-Jin Yang***, Yu-Jin Jegal**, Seong-Young Nam*, Jin Kim***, and Ji-Whan Ahn**t \\ *Korea Institute of Geoscience and Mineral Resources, Daejeon 305-350, Republic of Korea \\ **Department of Geology and Environmental Science, Chungnam National University, Daejeon 305-764, Republic of Korea \\ ***Department of Energy Resources Engineering, Inha University, Incheon 402-751, Republic of Korea \\ (Received February 11, 2014; Revised March 6, 2014; Accepted March 7, 2014)
}

\begin{abstract}
Quicklime $(\mathrm{CaO})$ is generally obtained through the calcination of limestone, the main component of which is calcium carbonate $\left(\mathrm{CaCO}_{3}\right)$. Quicklime generates high-temperature heat when reacting with water, forming slaked lime $\left(\mathrm{Ca}(\mathrm{OH})_{2}\right)$. The industrial sectors for limestone are determined by the hydraulic activity of slaked lime, which is obtained by measuring temperature changes during the hydration reaction. Accordingly, this study examined the different crystallographic characteristics of limestone as affected by the geological origins of the regions where the limestones were produced, and how these characteristics affected hydraulic activity. Six limestone samples were collected from the Jecheon and Cheongsong areas and the hydraulic activities were measured in accordance with KS E 3077. The results indicate that limestone produced in the Cheongsong area, recrystallized through metamorphism caused by hydrothermal alteration, hada larger grain size of calcite than that of the Jecheon area, and displays a tendency of changing to marble. Limestone from the Cheonsong area showed more radical reaction in the early stage of hydration compared to that ofthe Jecheon area. In addition, it was revealed that limestone having more impurities like $\mathrm{SiO}_{2}$ have lower hydraulic activity.
\end{abstract}

Key words : Limestone, Crystallinecalcite, $\mathrm{SiO}_{2}, \mathrm{Hydraulic}$ activity

\section{Introduction}

$\mathbf{R}$ eserves of limestone, which is mainly composed of $\mathrm{CaCO}_{3}$, equal 8.1 billion tons in South Korea, but the volume of high-grade limestone with at least $52 \mathrm{wt} \% \mathrm{CaO}$ only accounts for 12 percent of the total deposits. ${ }^{1)}$ Despite the small amount of high-grade limestone deposits, the cement industry accounts for almost 75 percent of the total domestic demand for limestone and research is actively being conducted to create high added value limestone and on its effective use. ${ }^{2)}$

Limestone is decarbonated after calcination and turns into quicklime $(\mathrm{CaO})$. This product reacts with water to produce slaked lime $\left(\mathrm{Ca}(\mathrm{OH})_{2}\right)$, and the temperature changes during this hydration reaction are measured to calculate the hydraulic activity of quicklime. The hydraulic activity varies according to the calcination temperature. Quicklime created through hard burning has smaller specific surface area than that created through soft burning, and is often used for steel manufacture due to its low hydraulic activity. Meanwhile, quicklime created through soft burning, featuring large specific surface area and high hydraulic activity, is frequently used for chemical uses or for compounding pre-

'Corresponding author: Ji-Whan Ahn

E-mail : ahnjw@kigam.re.kr

Tel : +82-42-868-3578 Fax : +82-42-861-3990 cipitated calcium carbonate (PCC). ${ }^{3)}$ The hydraulic activity of quicklime produced from limestone is a crucial factor in determining the industrial applications and sectorsfor limestone. Therefore, this study examines the geological background of the regions where limestone depositsare found. Furthermore we analyze whether the regional properties affect the crystals of limestone and how they have an impact on the hydraulic activity of calcium oxide.

Limestone is a carbonate sedimentary rock that is sensitive to diagenetic alteration. It is obtained in a developable form due to the influence of the secondary diagenetic alteration or metamorphism. Due to the influence of the secondary diagenetic alteration or metamorphism, the mineralogical characteristics and chemical composition of limestone vary in different regions. ${ }^{4)}$ The limestone deposits in Korea consist of the Great Limestone Series of the Joseon System in the Paleozoic era, the Hongjum Series and the Gabsan formation of the Carboniferous Period of the Pyeongan Systemand metasedimentary of an unknown period, all categorized by the geological backgrounds and deposit types. ${ }^{5}$ Limestones are classified ascrystalline limestone type, marble type, micro- and mega-crystalline calcite types on the basis of their composition, crystallinity, and mineral facies. ${ }^{3)}$ Most high-grade limestones in Korea have undergone alteration and accompany hydrothermally altered ore. However, the Gabsan formation and Yeongheung formations including Daesung(DS) limestone in the Jecheon area have rather low 
levels of alteration compared to other regions, thereby showing a type of crystalline limestone close to the source rock. $^{4,6)}$ In addition, in the Cheongsong region, where Hwangmok(HM) limestone was collected, crystalline limestone is irregularly intergrown in a lenticular shape in the granite gneiss, banded gneiss, and amphibolite rocks. Macrocrystalline limestone is also found in this region. ${ }^{7}$

This study analyzed four DS samples collected at San 115, Jajak-dong, Jecheon-si, Chungcheongbuk-do and two HM samples collected at 892 Hwangmok-ri, Cheongsong-gun, Gyeongsangbuk-do to identify how the characteristics of limestones having different geological backgrounds affect the hydraulic activity of quicklime.

\section{Experimental Procedure}

This study analyzed four limestone samples from the Jecheon area and two limestone samples from the Cheongsong area. The Mungok formation of the Ordovician period is distributed in the Jecheon area, conformably covered with the Yeongheung formation, which is again covered unconformably with the Gabsan formation, linearly distributed from Danyang (north-northwest) to Jecheon (south-southeast) ${ }^{5,8)}$ Hwangmok-ri is mostly covered with metamorphic rocks, igneous rocks of the early and middle periods of the Mesozoic era, and sedimentary rocks of the Cretaceous period. Also, crystalline limestone, granitic gneiss, and amphibolites of the Precambrian era are conformably distributed, consisting of Cheongsong granite and dykes of the Jurassic period of the Mesozoic era that interpenetrated in the later stage. ${ }^{7}$

X-ray fluorescence (XRF; XRF 1700, Shimadzu) was used to analyze the chemical components of the limestone, and polarizing microscopy was conducted to analyze the crystallographic features. The manufacture of quicklime and tests for measuring the hydration activity were conducted in conformity to Korean Standard (KS E 3077: Testing method for hydraulic activity of limestone used to precipitate calcium (arbonate). ${ }^{9)}$

Each of the six samples was pulverized with a jaw crusher and then selected in a range of $19-31.5 \mathrm{~mm}$ by using a sieve. The separated limestone was burnt for $2 \mathrm{~h}$ at $1,000^{\circ} \mathrm{C}$ in an electric furnace to obtain quicklime. After cooling, the limestone was packed in a vacuum pack in order to prevent any reaction with carbon dioxide or with moisture in the air, and was then stored in a desiccator.
Using a device to measure heat (KS L 5121), the quicklime (30 g) was passed through a 200-mesh sieve and distilled water $(120 \mathrm{ml})$ and stirred at $400 \mathrm{rpm}$ under $25^{\circ} \mathrm{C}$ to examine the hydration reaction for 30 minutes. When the reaction started, the temperature changes were recorded every five seconds. Reacting to water, quicklime undergoes an exothermic reaction releasing high heat, as expressed below.

$$
\mathrm{CaO}+\mathrm{H}_{2} \mathrm{O} \rightarrow \mathrm{Ca}(\mathrm{OH})_{2}+15.59 \mathrm{Kcal} / \mathrm{mol}
$$

As suggested in the KS E 3077, the temperature changes occurring up to 30 seconds after hydration began were measured to evaluate the hydraulic activity of the limestone. The limestone hydraulic activity was calculated according to the following formula.

$$
A=T_{30 \mathrm{~s}}-T_{0}=\Delta T
$$

where

A : $\quad$ Hydraulic activity $\left({ }^{\circ} \mathrm{C}\right)$ of limestone

$T_{30 \mathrm{~s}}$ : Temperature $\left({ }^{\circ} \mathrm{C}\right)$ at 30 seconds from the start of hydration

$T_{0}: \quad$ Temperature $\left({ }^{\circ} \mathrm{C}\right)$ before the start of hydration

$\Delta T: \quad$ Value $\left({ }^{\circ} \mathrm{C}\right)$ of temperature change from the start of hydration to 30 seconds

Slaked lime obtained after 30-minute hydration was dried in an oven at $80^{\circ} \mathrm{C}$ and then stored in a vacuum pack. Analysis of the mineral species of quicklime and slaked lime powder were conducted using an X-ray diffractometer (XRD; D/Max-1200, Rigaku), while a whiteness tester (Kett Electric Laboratory, Japan) was used to measure the whiteness index.

\section{Results and Discussion}

\subsection{Basic Properties of Limestone and Crystallo- graphic Analysis}

To identify the factors that affect the hydraulic activity of quicklime, besidesthe factor of $\mathrm{CaO}$ content, we used relatively high-grade limestone samples with similar levels of impurities content. The chemical components of the six samples are listed in Table 1 . All of the samples are highgrade limestones containing high $\mathrm{CaO}$ within a range of 54.02-55.61 wt\%. Among the DS limestone samples from the Jecheon area, DS3 has the highest $\mathrm{SiO}_{2}$ content; DS3

Table 1. Chemical Components of the Limestone Samples Analyzed Using X-ray Fluorescence (XRF)

\begin{tabular}{cccccccccccc}
\hline & $\mathrm{SiO}_{2}$ & $\mathrm{Al}_{2} \mathrm{O}_{3}$ & $\mathrm{Fe}_{2} \mathrm{O}_{3}$ & $\mathrm{CaO}$ & $\mathrm{MgO}$ & $\mathrm{K}_{2} \mathrm{O}$ & $\mathrm{Na}_{2} \mathrm{O}$ & $\mathrm{TiO}_{2}$ & $\mathrm{MnO}_{2}$ & $\mathrm{P}_{2} \mathrm{O}_{5}$ & Igloss \\
\hline $\mathrm{DS} 1$ & 0.09 & 0.02 & 0.15 & 55.57 & 0.28 & 0.02 & $<0.02$ & $<0.01$ & 0.01 & 0.01 & 43.61 \\
$\mathrm{DS} 2$ & 0.03 & $<0.01$ & 0.12 & 55.44 & 0.29 & 0.02 & $<0.02$ & $<0.01$ & 0.01 & 0.01 & 43.73 \\
$\mathrm{DS} 3$ & 0.28 & 0.02 & 0.34 & 54.49 & 0.84 & 0.02 & $<0.02$ & $<0.01$ & 0.07 & 0.02 & 43.88 \\
$\mathrm{DS} 4$ & 0.01 & $<0.01$ & 0.28 & 54.77 & 0.86 & 0.02 & $<0.02$ & $<0.01$ & 0.03 & 0.01 & 43.87 \\
$\mathrm{HM} 5$ & 1.97 & 0.11 & 0.07 & 54.02 & 0.64 & 0.03 & $<0.02$ & $<0.01$ & $<0.01$ & 0.03 & 42.73 \\
$\mathrm{HM} 6$ & 0.15 & $<0.01$ & 0.03 & 55.61 & 0.27 & 0.02 & $<0.02$ & $<0.01$ & $<0.01$ & 0.03 & 43.61 \\
\hline
\end{tabular}



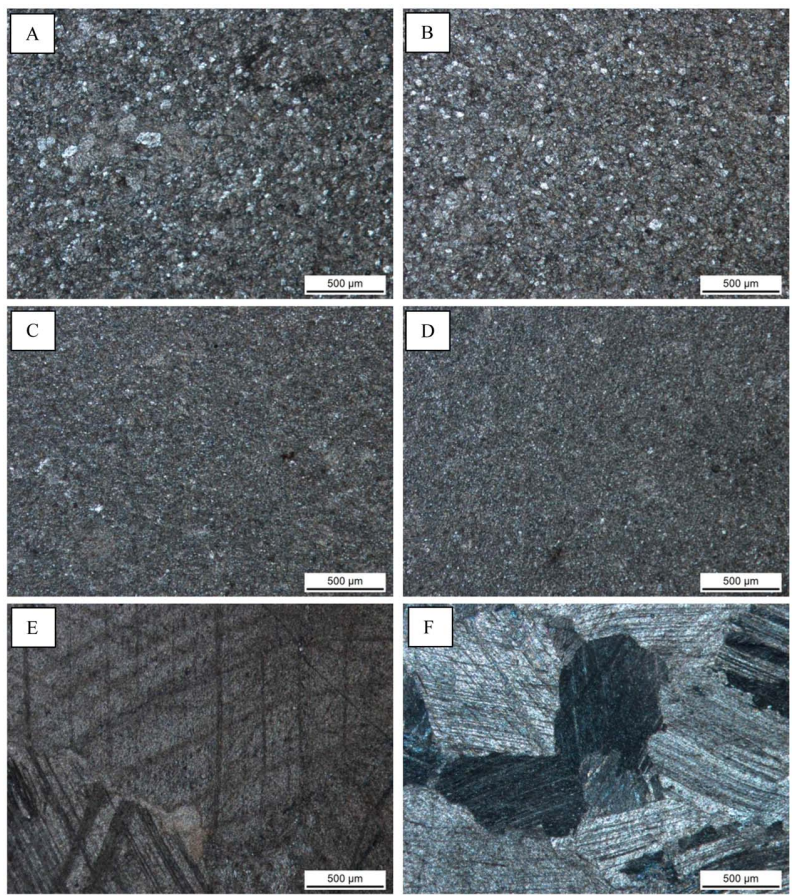

Fig. 1. Photomicrographs of domestic high-Ca limestones; A(DS1): Fine-grained crystalline calcite type limestone. B(DS2): Fine-grained crystalline calcite type limestone. C(DS3): Micro crystalline calcite type limestone. D(DS4): Micro crystalline calcite type limestone. E(HM5): Megacrystalline calcite type limestone. F (HM6): Coarse crystalline marble type limestone.

and DS4 show high content of $\mathrm{Fe}_{2} \mathrm{O}_{3}$ and $\mathrm{MgO}$; and DS2 contains the smallest amount of impurities. The two HM limestone samples collected in Cheongsong area have $\mathrm{CaO}$ content of $54.02 \mathrm{wt} \%$ and $55.61 \mathrm{wt} \%$, respectively. The content of $\mathrm{SiO}_{2}$ is $1.97 \mathrm{wt} \%$ in $\mathrm{HM} 5$, the highest value among the samples.

Considering only the results of the limestone chemical analysis, it is expected that DS1, DS2, and HM6 will display similar characteristics in terms of whiteness index and hydraulic activity, since the samples contain similar levels of impurities and are high-grade limestone with similar $\mathrm{CaO}$ content. However, an analysis of thin sections of limestone using a polarizing microscope showed that HM6 has coarser crystalline calcite grains than those of DS1 and DS2. Thin sections of the four DS samples were examined with open nicol and the two HM samples with crossed nicol. The results of the polarizing microscopy analysis are provided in Fig. 1. The calcite crystals of the four DS samples are mostly found to be micro or smaller size, while the two HM samples have comparably larger calcite crystals, with clearly observable twins and cleavages. Other samples from the same area have shown similar crystallographic characteristics.

Whiteness index does not greatly influence the uses of limestone, but it serves as an indirect indicator of the quality and impurities of the limestone. The presence of mineral
Table 2. Whiteness Index of Limestone Analyzed Using Whiteness Tester

\begin{tabular}{ccccccc}
\hline & DS1 & DS2 & DS3 & DS4 & HM5 & HM6 \\
\hline W.I. & 76 & 80.8 & 57.1 & 66.1 & 80.6 & 92.0 \\
\hline
\end{tabular}

impurities with special streaks of colors lower the whiteness, and dolomite and carbonitride decrease the whiteness, too. ${ }^{4}$ Solely based on the chemical composition of the six limestone samples, it was expected that their whiteness index would not show significant differences since all six samples are high-grade and have similar content of impurities. However, the experimental results revealed different values, descending from HM6 > HM5 > DS2> DS1> DS4 > DS3 (Table 2).

Table 2 shows that the two HM samples generally have higher whiteness value than the four DS samples. This is because the Cheongsong area, where HM samples were collected, produces metasedimentary rocks as a result of hydrothermal alteration and metamorphism. On the other hand, limestone in Jecheon, where the DS samples were collected, underwent less hydrothermal alteration compared to other regions. Thus, they contain impurities that lower the whiteness index, such as carbonitride originating from the source rocks. ${ }^{4}$ In particular, DS3 and DS4 show lower whiteness value than other samples due to dolomite, as shown in the peak of the XRD analysis, and iron-containing reddish mafic minerals partially contained in the limestone (Fig. 2). Also, the whiteness indexes of HM5 and HM6 are significantly high. This is because the limestone deposits in the Cheonsong area have undergonere crystallization through hydrothermal alteration and metamorphism, increasing the size of crystals and their structural density. Consequently, whitish limestone polishes more than generally known finegrained crystalline calcite type limestone. ${ }^{10)}$

\subsection{Effect of Crystallographic Characteristics of Limestone on the Hydraulic Activity}

To observe the hydraulic reaction of quicklime, four samples were selected: DS1, DS2, HM5, and HM6, which had similar chemical composition and wereless affected by impurities such as $\mathrm{Fe}, \mathrm{Si}$, or $\mathrm{Mg}$. For each sample, five experiments were conducted in compliance with the Korean Standard, and the temperature changes were recorded every five seconds. The temperature data were subject to errors due to factors including the velocity of injecting the quicklime and distilled water into the container for the hydraulic reaction and the insulation level of the container stopper.

The difference between initial temperature $\left(25^{\circ} \mathrm{C}\right)$ and the temperature after 30 seconds of hydration starts is termed hydraulic activity, and the experiment results were as follows: DS1 $\left(38.2^{\circ} \mathrm{C}\right)$, DS2 $\left(41.0^{\circ} \mathrm{C}\right)$, HM5 $\left(54.7^{\circ} \mathrm{C}\right)$, and HM6 $\left(77.4^{\circ} \mathrm{C}\right)$. The changes of temperature for 30 minutes are shown in Fig. 3, which exhibits that the temperature changes of quicklime vary according to the characteristics 

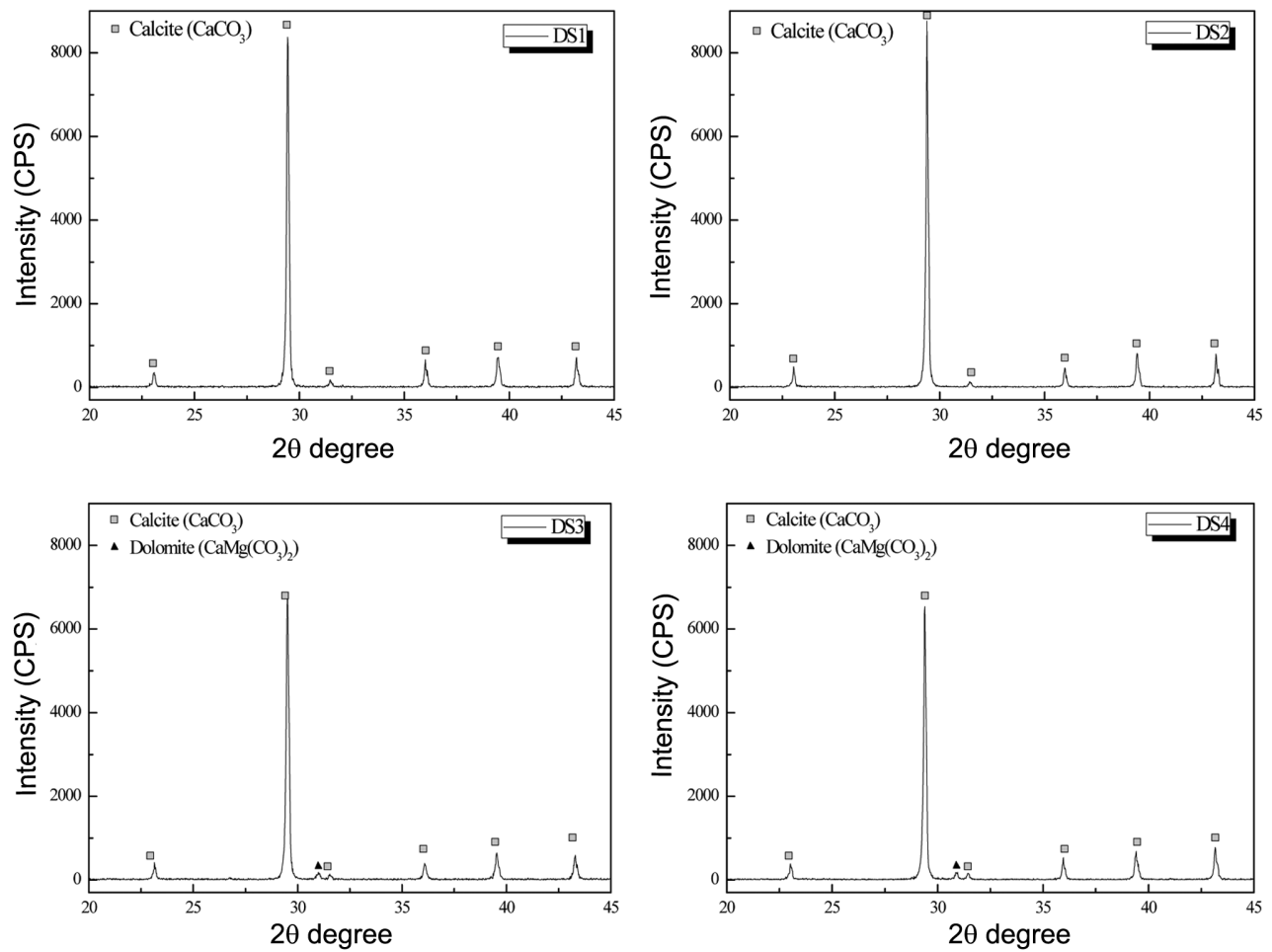

Fig. 2. XRD patterns of limestone samples: DS1, DS2, DS3, and DS4.

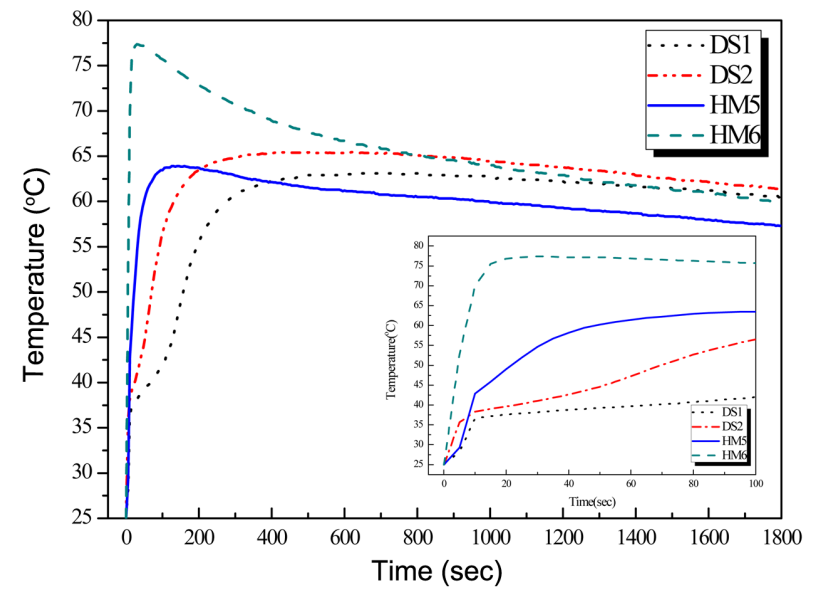

Fig. 3. Changes of temperature during hydration of limestone at initial temperature of $25^{\circ} \mathrm{C}$ : DS1, DS2, HM5, and HM6.

observed in the results of the chemical analysis and polarizing microscopy analysis conducted earlier.

The initial reaction of HM6 is different from the others, showing a sharp increase in temperature as soon as hydration starts. HM5 shows an immediate increase in temperature but relatively lower than HM6. The temperature of DS1 and DS2 increases, not dramatically but steadily. The causes of the results are associated with the crystallographic features of the limestone. Mega-crystalline calcite type limestones like HM5 and HM6 fail to maintain their original shape during calcination and are easily broken, negatively affecting the furnace. Disintegration of quicklime occurs because of the crystalline structure or condition of quicklime and the tendency of thermal expansion by theanisotropic calcite crystals. ${ }^{11)}$ As a result, mega-crystalline calcite type limestones like HM5 and HM6 which have large surface area to react with water, show high hydraulic activity. However, mega-crystalline calcite type limestone is mainly used for manufacturing ground calcium carbonate (GCC) since it is easily broken and disintegrated.

The hydration experiments confirmed that mega-crystalline calcite type limestones like HM samples have higher hydraulic activity than micro crystalline calcite type limestones like DS samples. This indicates that mega-crystalline calcite type limestone, the use of which has been limited to the GCC industry, can be utilized in industries that require high activity with water and high temperature in the initial stage of hydration, assuming that the issues regarding damage to the furnace canbe solved.

The XRD analysis of the quicklime of HM5 and HM6 (HM5-1 and HM6-1, respectively) shows peaks indicating quicklime (Fig. 4). Comparing the hydration experiment results of HM5 and HM6, it is observed that the hydration temperature of HM5 containing quartz changes at a slower pace than that of HM6, but faster than that of DS2. This is consistent with research results showingthat the existence of impurities such as $\mathrm{SiO}_{2}, \mathrm{MgO}$, and $\mathrm{Fe}_{2} \mathrm{O}_{3}$ in limestone contributes to lowering its hydraulic activity. ${ }^{12}$

Generally, chemical composition is used to classify limestone. For this reasons, limestone with high $\mathrm{CaO}$ is anticipated to have high whiteness and hydraulic activity. 


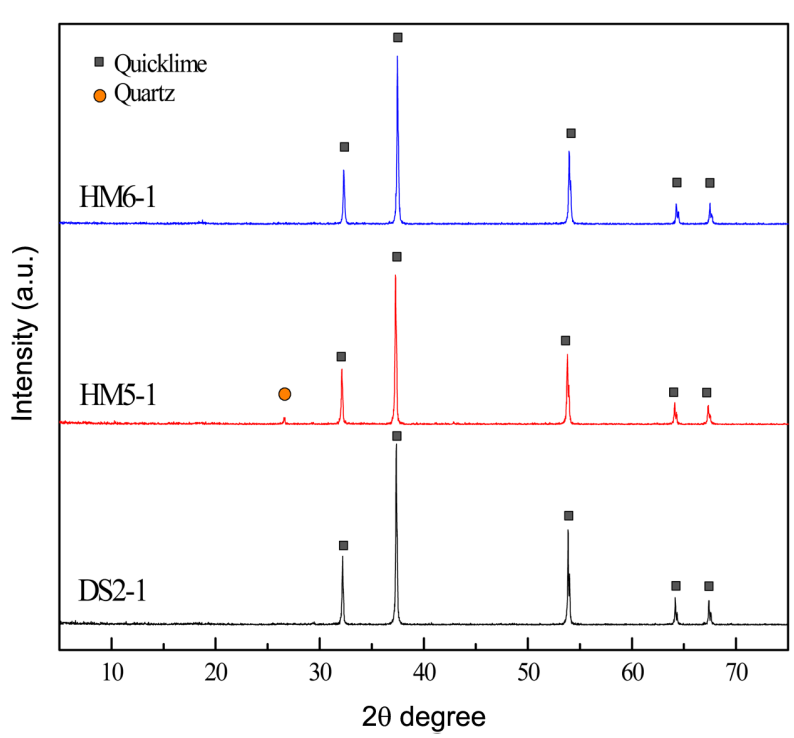

Fig. 4. XRD patterns of quicklime: DS2-1, HM5-1, and HM6-1.

Table 3. Anticipated and Measured Data Depending on $\mathrm{CaO}$ Contents

\begin{tabular}{|c|c|c|c|c|c|c}
\hline Limestone & DS1 & DS2 & DS3 & DS4 & HM5 & HM6 \\
CaO (\%) & 55.57 & 55.44 & 54.49 & 54.77 & 54.02 & 55.61 \\
\hline Whiteness Index \\
\hline Expected & \multicolumn{5}{c}{ Similar W.I. (bright) } \\
\hline Measured & Low & High \\
\hline Hydraulic Activity of Quicklime \\
\hline Expected & Similar hydraulic activity; high due to high CaO \\
\hline Measured & \multicolumn{5}{c}{ Low } \\
\hline Crystallographic Characteristics \\
\hline Expected & Similar or cannot expect \\
\hline Measured & Micro/Fine \\
\hline
\end{tabular}

However, the measured data here show a completely contrary pattern. Table 3 presents the summarized results. All the limestone samples have high $\mathrm{CaO}$ content but show different results depending on region and its geological origin.

\section{Conclusion}

This study examined the limestone generating mechanisms of the regions where limestone samples were collected. Six limestone samples fromthe Jecheon(Danyang, Chungcheongbuk-do) and Hwangmok areas(Cheongsong, Gyeongsangbuk-do) were used. Also, experiments identified how such crystallographic characteristics impact the hydraulic activity of quicklime produced from the various samples.

DS limestones of Jechoen were subject to less hydrothermal alteration and metamorphism, resulting in micro-crystalline calcite, while HM limestones exhibit larger grain sizes and distinct features of twins and cleavages as a result of recrystallization following hydrothermal alteration. Therefore, whitish mega-crystalline calcite type limestones like the HM samples have shown higher hydraulic activity than pinkish gray limestones with micro-crystalline calcite type limestone like the DS samples. ${ }^{10}$ Also, the research revealed that limestones with more impurities, such as $\mathrm{SiO}_{2}$, tended to have lower hydraulic activity. ${ }^{12)}$

Although mega-crystalline calcite type limestone is easily disintegrated by thermal reaction, it is necessary to study the utility of its outstanding hydraulic activity compared to micro crystalline calcite type limestone. Furthermore, it is imperative to formulate criteria for limestone classification that reflects hydraulic activity in addition to the chemical composition of the limestone. The researchers of this study plan to further examine the impact of crystallographic and geological characteristics of limestone on applications in a variety of industrial sectors such as the manufacture of aragonite precipitated calcium carbonate, papermaking, and plastic processing, as well as classification criteria reflecting such factors and effective ways to utilize mega-crystalline calcite type limestone.

\section{Acknowledgment}

This research was conducted in 2013 with support from the Energy Technology Development Project [2013T100 100021] of the Korea Institute of Energy Technology Evaluation and Planning, financed by the Ministry of Trade, Industry and Energy.

\section{REFERENCES}

1. S. J. Kim, "A general Survey of Mining Industry Report (in Korean)," pp. 5, Korea Resources Corporation (KORES), 2010.

2. H. K. Shin, H. S. Lee, Y. N. Kim, and J. E. Kim, "Fabrication and Application of Multifuctional Lime (in Korean)," pp. 3-6, Korea Institute of Science and Technology Information (KISTI) 2002-R-NM11-P-03-1-000, 2007.

3. A. Moropoulou, A. Bakolas, and E. Aggelakopoulou, "The Effect of Limestone Characteristics and Calcinations Temperature to the Reactivity of the Quicklime," Cem. Concr. Res., 31 [4] 633-39 (2001).

4. J. H. Noh, S. J. Oh, and K. J. Kim, "Applied-mineralogical Study on the Mineral Facies and Characteristics of Domestic High-Ca Limestone (in Korean)," J. Miner. Soc. Korea, 17 [4] 339-55 (2004).

5. S. S. Choi, "A Study on the Gabsan Formation Limestone Deposits in Korea(in Korean)," pp. 2-3, in M. D. thesis, Kangwon University, 2007.

6. K. S. Yoon, W. S. Yoon, I. S. Kim, U. J. Jeong, M. J. Yoon, B. R. Im, and J. H. Kim, "Accurate Research Report, Limestone: Danyang-Maepo Area (in Korean)," pp. 32-38, Korea Resources Corporation (KORES) DS2012-LS(IV), NMT(II), 2012.

7. K. Y. Oh, C. W. Seo, Y. K. Kim, J. N. Kang, and K. S. Hong, "Accurate Research Report, Limestone: Seokbyeongsan 
area-Cheonji Area (in Korean)," pp. 31-48, Korea Resources Corporation (KORES) DS2008-LS(I), 2008.

8. S. I. Park, H. K. Lee, and S. H. Lee, "Characteristics and Distribution Pattern of Carbonate Rock Resources in Kangwon Area: The Gabsan Formation around the Mt. Gachang Area, Chungbuk, Korea(in Korean)," J. Kor. Earth Sci. Soc., 21 [4] 437-48 (2000).

9. Korean Standard,"KS E 3077: Testing Method for Hydraulic Activity of Limestone used to Precipitated Calcium Carbonate(in Korean)," (2006).

10. J. H. Noh and H. C. Lee, "Calcination Characteristics of
High-purity Limestone from Pungchon Limestone in Quicklime Manufacture(in Korean)," J. Miner. Soc. Korea, 21 [2] 209-224 (2008).

11. R. Hedin, "Changes Occurring in the Limestone during Heating before Calcination," Swed. Cem. Conc. Res. Inst. Bull., 2334 (1954).

12. K. H. Cho, "A Study on Calcination and Hydraulic Activity of Limestone Affecting the Synthesis of Precipitated Calcium Carbonate (in Korean)," pp. 76-77, in Ph. D thesis, Kwangwoon University, 2009. 